\title{
Conservação pós-colheita de mangaba em função da maturação, atmosfera e temperatura de armazenamento
}

\author{
Postharvest conservation of mangaba fruit as a function of maturity, atmosphere, and storage temperature
}

\author{
Adriana Ferreira dos SANTOS ${ }^{1}$, Silvanda de Melo SILVA ${ }^{2 *}$, \\ Rejane Maria Nunes MENDONÇA ${ }^{1}$, Ricardo Elesbão ALVES ${ }^{3}$
}

\begin{abstract}
Resumo
Nesse trabalho, avaliou-se a influência de Atmosfera Modificada (AM) por filme de PVC na conservação pós-colheita de mangabas colhidas nos estádios de maturação Verde (V), início da pigmentação amarela (IP) e fruto amarelo com leves manchas vermelhas (AV) e armazenadas sob refrigeração $\left(10 \pm 0,5^{\circ} \mathrm{C}\right.$ e $90 \pm 2 \%$ UR) e sob condições ambientes $\left(23 \pm 2{ }^{\circ} \mathrm{C}\right.$ e $75 \pm 2 \%$ UR). O uso de AM associada à refrigeração resultou em menores perdas de massa fresca, permitiu a manutenção da vida útil pós-colheita dos frutos durante 15 dias, mantendo a aparência geral acima do limite de aceitação pelo consumidor, para os três estádios de maturação avaliados. Mangabas colhidas no estádio de maturação verde não desenvolveram a coloração característica e apresentaram visível incidência de danos pelo frio quando mantidas sob refrigeração. Frutos colhidos no estádio de maturação IP, mantidos sob AM e refrigeração, amadureceram normalmente e apresentaram melhor aparência após 15 dias de armazenamento, quando comparados com mangabas colhidas no estádio AV e mantidas sob as mesmas condições.

Palavras-chave: Hancornia speciosa; filme de PVC; estádio de maturação; qualidade pós-colheita; armazenamento refrigerado; frutas nativas.
\end{abstract}

\begin{abstract}
It was evaluated the influence of modified atmosphere (MA) by PVC film and refrigeration on postharvest conservation of mangaba fruits harvested at the maturity stages green $(\mathrm{G})$, yellow pigment initiation (PI), and yellow fruit with light reddish spots (YR) was evaluated. They were stored under refrigeration $\left(10 \pm 0.5^{\circ} \mathrm{C}\right.$ and $\left.90 \pm 2 \% \mathrm{RH}\right)$ and room conditions $\left(23 \pm 2{ }^{\circ} \mathrm{C}\right.$ and $\left.75 \pm 2 \% \mathrm{RH}\right)$. The use of MA associated with refrigeration resulted in lower losses of fresh mass allowing the quality maintenance of postharvest fruits during 15 days of storage. The overall visual appearance of the fruits was kept above the acceptance limit in all maturity stages evaluated. Mangaba fruit harvested at the maturity stage green did not develop the characteristic color and presented visible incidence of freezing and chill damage when kept under refrigeration. Fruits harvested at the maturity stage PI, kept under MA and refrigeration, ripened normally and presented better appearance after 15 days of storage when compared with mangaba fruits harvested at the YR maturity stage and kept under similar storage conditions. Keywords: Hancornia speciosa; PVC film; maturity stage; postharvest quality; storage under refrigeration; native fruit.
\end{abstract}

\section{Introdução}

A mangabeira (Hancomia speciosa Gomes) produz um fruto bastante apreciado pelas suas excelentes características físicas (VIEIRA NETO, 1997), aroma e sabor, associados ao elevado valor nutritivo (MANICA, 2002). O fruto, a mangaba, apresenta comportamento típico de fruto climatérico (MOURA, 2005; ALVES et al., 2006). A mangaba apresenta polpa branca, agridoce e aromática, podendo ser consumida in natura ou no preparo de geléias, sorvete, licor, doce, refresco, vinho e vinagre (BORGES et al., 2000). No entanto, a mangaba é um fruto extremamente perecível (LEDERMAN et al., 2000) e, portanto, suscetível a danos mecânicos durante a colheita, transporte e manuseio, o que representa um sério obstáculo para a comercialização (CARNELOSSI et al., 2004).

A elevada taxa de perecibilidade de frutos tropicais, como a mangaba, torna necessário que técnicas adequadas de manuseio e conservação sejam desenvolvidas visando aumentar sua vida útil pós-colheita (ALVES et al., 2006).

A qualidade pós-colheita dos frutos está relacionada com a minimização da taxa de deterioração, ou seja, manutenção da firmeza, cor, aparência, visando mantê-los atraentes ao consumidor por um período de tempo mais longo (CHITARRA; CHITARRA, 2005). O uso de Atmosfera Modificada (AM) tem se mostrado eficiente em reduzir as taxas de respiração e transpiração (BEN-ARIE; ZUTKHI, 1992), ampliando a vida útil de frutos e hortaliças (BEN-YEHOSHUA, 1987; SANTOS et al., 2006). O emprego de AM, pelo uso de filmes flexíveis, como o de cloreto de polivinila (PVC), estabelece uma composição gasosa no interior da embalagem diferente da do ar, pela redução da concentração de $\mathrm{O}_{2}$ e elevação do $\mathrm{CO}_{2}$, que pode reduzir a atividade metabólica do produto (KAYS, 1997).

\footnotetext{
Recebido para publicação em 12/7/2007

Aceito para publicação em 4/1/2009 (002673)

Programa de Pós-Graduação em Agronomia, Centro de Ciências Agrárias, Universidade Federal da Paraíba - UFPB, CEP 58397-000, Areia - PB, Brasil,

E-mail:rejane@cca.ufpb.br; adrefesantos@yahoo.com.br

${ }^{2}$ Laboratório de Biologia e Tecnologia Pós-Colheita, Departamento de Ciências Fundamentais e Sociais, Centro de Ciências Agrárias,

Universidade Federal da Paraíba - UFPB, CP 04, CEP 58397-000, Areia - PB, Brasil, E-mail: silvasil@pq.cnpq.br

${ }^{3}$ EMBRAPA Agroindústria Tropical, Laboratório de Tecnologia Pós-Colheita, CEP 60511-110, Fortaleza-CE, Brasil

${ }^{*}$ A quem a correspondência deve ser enviada
} 
Para atingir outros mercados, é necessário o desenvolvimento de técnicas que propiciem a conservação e agregação de valor do fruto. O emprego de tecnologias pós-colheita, portanto, vem incrementar a cadeia produtiva da mangaba prolongando sua vida útil e tornando viável seu transporte a longas distâncias, alcançando outros mercados, propiciando sustentabilidade à cultura e oferecendo melhor remuneração ao produtor (VILLACHIA, 1996).

Frente ao exposto, verificou-se a influência do estádio de maturação $(\mathrm{V}=$ verde; $\mathrm{IP}$ = início de pigmentação amarela; e $\mathrm{AV}=$ amarelo com leves manchas vermelhas), condições de atmosfera (ambiente (AA) ou modificada (AM)) e de temperatura de armazenamento (10 e $23^{\circ} \mathrm{C}$ ) na conservação pós-colheita de mangaba.

\section{Material e métodos}

Os frutos do clone Nísia Floresta 1 utilizados no experimento foram provenientes de plantas de aproximadamente quatro anos, selecionadas do Jardim Clonal da Estação Experimental de mangabeira da Empresa Estadual de Pesquisa Agropecuária da Paraíba-Emepa-PB, situada no Município de João Pessoa, no Litoral Paraibano. Os frutos foram colhidos diretamente da planta nos estádios de maturação Verde (V), início da pigmentação amarela (IP) e fruto amarelo com leves manchas vermelhas (AV) - (Figura 1). A colheita ocorreu entre sete e nove horas da manhã. Logo após a colheita, os frutos foram transportados em caixas de poliestireno expandido para o Laboratório de Biologia e Tecnologia Pós-colheita do Centro de Ciências Agrárias da Universidade Federal da Paraíba, Areia-PB. No laboratório, os frutos foram selecionados de acordo com o estádio de maturação e ausência de injúrias. Após a seleção, como tratamento antifúngico, os frutos foram imersos por 20 minutos em solução de hipoclorito de sódio comercial a 0,5\%. Grupos de 12 frutos, compondo aproximadamente $250 \mathrm{~g}$, em três repetições, foram acondicionados em bandejas de poliestireno expandido com dimensões $250 \mathrm{~mm}$ x $150 \mathrm{~mm} \times 25 \mathrm{~mm}$.

Para a modificação da atmosfera (AM), metade do total de bandejas foi envolvida com filme de cloreto de polivinila (PVC) de $13 \mu \mathrm{m}$ de espessura. A outra metade das bandejas foi mantida sem filme de PVC, caracterizando armazenamento sob Atmosfera Ambiente (AA). Os frutos sob AM e AA, foram

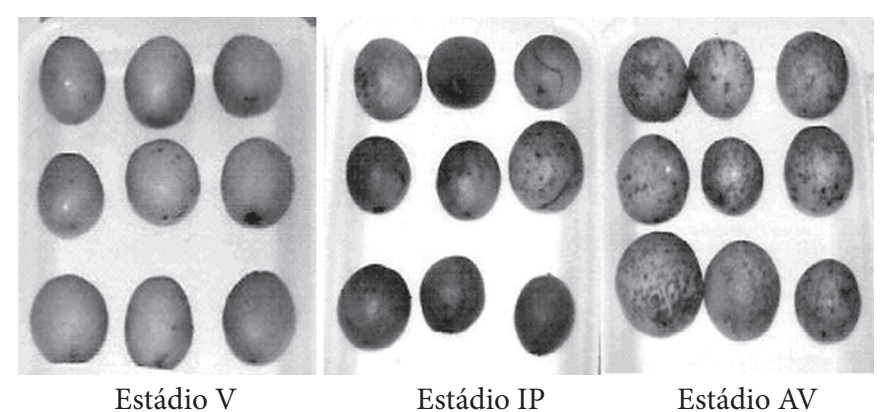

Figura 1. Estádios de maturação em mangabas do clone Nísia Floresta, utilizados no experimento: Verde (V), início da pigmentação amarela (IP) e fruto amarelo com leves manchas vermelhas (AV). distribuídos aleatoriamente à temperatura de refrigeração $\left(10 \pm 0,5^{\circ} \mathrm{C}\right.$ e $90 \pm 2 \%$ UR $)$ e sob a condição ambiente $\left(23 \pm 2^{\circ} \mathrm{C}\right.$ e $75 \pm 2 \%$ UR). Para amostras mantidas sob refrigeração, as avaliações foram realizadas a cada três dias, durante 15 dias. Para frutos mantidos sob a condição ambiente, as avaliações foram realizadas a cada 2 dias durante 10 dias.

Foram avaliados: a perda de massa (\%), tomando como referência o peso inicial dos frutos; firmeza $(\mathrm{N})$, em duas posições equidistantes; pH; sólidos solúveis (SS - \%); acidez titulável (AT - \% de ácido cítrico); relação SS/AT (INSTITUTO ADOLFO LUTZ, 2005); cor subjetiva mediante escala de 1 a 5 (1- totalmente verde; 2 - fruto verde com início da pigmentação vermelho amarelado; 3 - fruto amarelo com leves manchas vermelhas; 4 - amarelo-avermelhado; 5 - fruto com 70\% da sua coloração vermelha e 30\% amarelo-escuro); aparência geral, realizada diariamente por 6 avaliadores não treinados, seguindo a escala de 1 (inaceitável) a 9 (excelente). O escore 4 correspondeu ao limite em que a aparência limitava a aceitação do produto por um consumidor médio. $\mathrm{O}$ delineamento experimental utilizado foi o inteiramente casualizado, em esquema de fatorial $(3 \times 2 \times 6)$, com 3 repetições de 12 frutos/parcela, no qual o fator 3 correspondeu aos estádios de maturação (V, IP e $\mathrm{AV}$ ), o fator 2 às atmosferas (AM e AA) e o fator 6 aos períodos de avaliação $(0,2,4,6,8$ e 10) para temperatura ambiente e $(0$, $3,6,9,12$ e 15) para a temperatura de $10^{\circ} \mathrm{C}$. Para as avaliações subjetivas, o delineamento foi parcela sub-subdividida no tempo $(3 \times 2 \times 6)$. As avaliações subjetivas foram analisadas depois de transformadas por $\sqrt{(X+1)}$. Os fatores foram submetidos à análise de variância. As médias foram comparadas pelo teste de Tukey a $5 \%$ de probabilidade e à análise de regressão polinomial.

\section{Resultados e discussão}

O emprego de Atmosfera Modificada (AM) por filme de PVC em mangabas colhidas nos três estádios de maturação avaliados, efetivamente reduziu a perda de massa durante o armazenamento tanto sob condição ambiente, quanto sob refrigeração (Figura 2).

A perda de massa excessiva é um dos principais fatores relacionados com a perda da qualidade comercial de frutos e hortaliças (MEDINA, 1984). A perda de massa para os frutos sob Atmosfera Ambiente (AA) aumentou gradativamente durante $\mathrm{o}$ armazenamento sob condições ambiente, atingido os valores médios de $25,28 \%$ para frutos no estádio $\mathrm{V}, 16,37 \%$ para frutos no estádio IP e 20,56\% para os frutos no estádio $\mathrm{AV}$, durante os 10 dias pós-colheita. A perda de massa para frutos mantidos sob Atmosfera Modificada (AM) foi significativamente inferior quando comparada à perda sob $\mathrm{AA}$, independentemente da temperatura de armazenamento. Para frutos mantidos sob refrigeração, a perda de massa foi significativamente inferior, embora tenha aumentado linearmente para os estádios V e AV durante 15 dias de armazenamento.

Com relação à firmeza, verificou-se efeito significativo para a atmosfera e estádios de maturação empregados nos experimentos em função dos períodos de armazenamento, para frutos mantidos sob a condição ambiente e refrigeração (Figura 3). 
Observa-se que os frutos mantidos sob AM apresentaram menor perda de firmeza durante o armazenamento. A perda da firmeza é uma característica geral do processo de maturação dos frutos (KAYS, 1997). O emprego de AM pode ter auxiliado a minimizar as transformações resultantes do amadurecimento do fruto, tais como a redução da taxa respiratória (MOURA, 2005), com consequente redução das perdas de matéria fresca e manutenção da firmeza, como também descrito por Alves et al. (2006).

O teor de Sólidos Solúveis (SS) para mangabas nos estádios $\mathrm{V}$, IP e $\mathrm{AV}$, não diferiu entre frutos mantidos sob $\mathrm{AA}$ ou $\mathrm{AM}$, ao final do período de armazenamento, independentemente da temperatura (Figura 4).
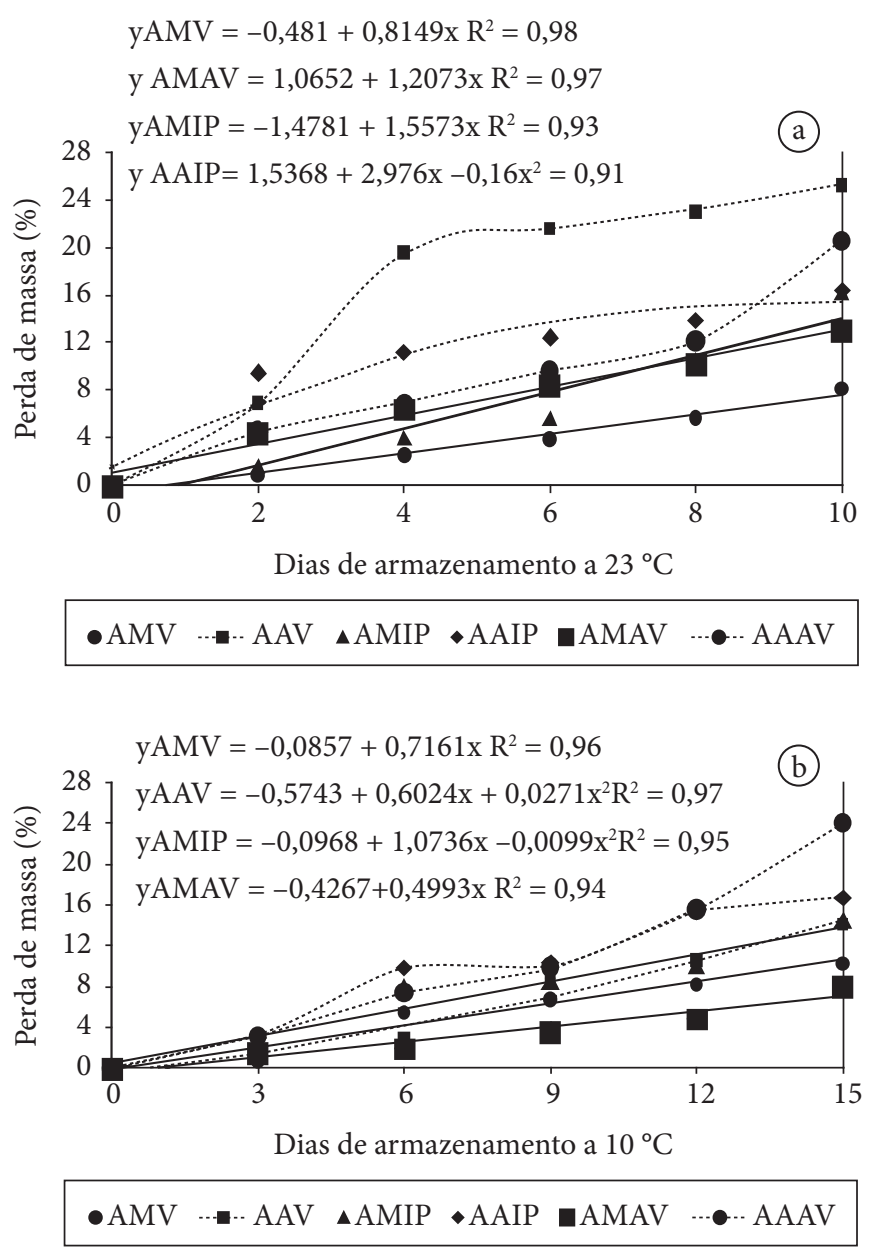

Figura 2. Perda de massa em mangaba decorrente do estádio de maturação, atmosfera e temperatura, durante o armazenamento sob a condição ambiente $\left(\mathrm{A}-23 \pm 2{ }^{\circ} \mathrm{C}\right)$ e sob refrigeração $\left(\mathrm{B}-10 \pm 0,5^{\circ} \mathrm{C}\right)$. Linha cheia: $\mathrm{AM}=$ atmosfera modificada; linha tracejada: $\mathrm{AA}=$ atmosfera ambiente; $\mathrm{AMV}$ = atmosfera modificada e estádio de maturação verde; $\mathrm{AAV}$ = atmosfera ambiente e estádio de maturação verde; AMIP = atmosfera modificada e estádio de maturação início da pigmentação; AAIP = atmosfera ambiente e estádio de maturação início da pigmentação; $A M A V$ = atmosfera modificada e estádio de maturação amarelo com leves manchas vermelhas; e AAAV = atmosfera ambiente e estádio de maturação amarelo com leves manchas vermelhas.
No entanto, verificou-se que os frutos no estádio AV apresentaram os teores mais elevados de SS, quando comparados aos estádios V e IP. Os menores teores de SS foram verificados em frutos no estádio $\mathrm{V}$, apresentando teores médios de 8,13 (AM) e 8,47 (AA) no final do armazenamento à temperatura ambiente (Figura 4a). Mangabas mantidas sob refrigeração apresentaram um aumento nos teores SS durante o armazenamento (Figura 4b). Durante a maturação de frutos climatéricos, o teor de sólidos solúveis totais tende a aumentar devido à biossíntese de açúcares solúveis ou à degradação de polissacarídeos. À medida que a maturação avança, os ácidos também podem

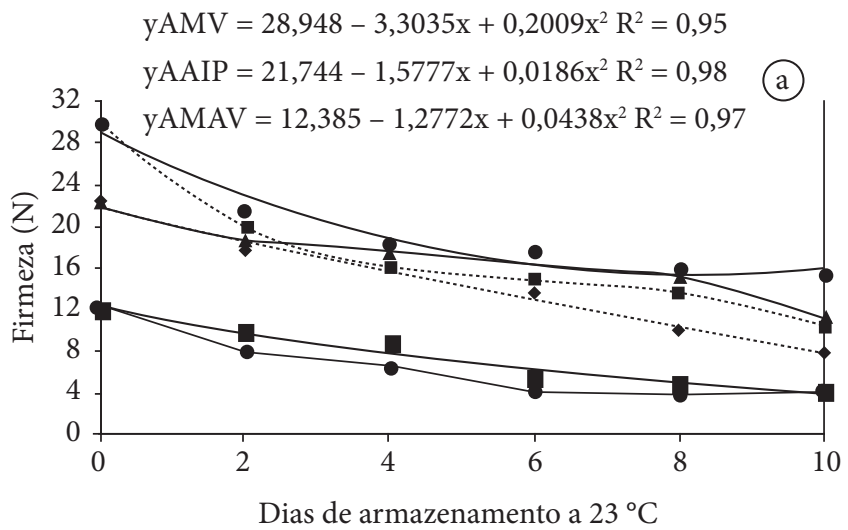

•AMV …

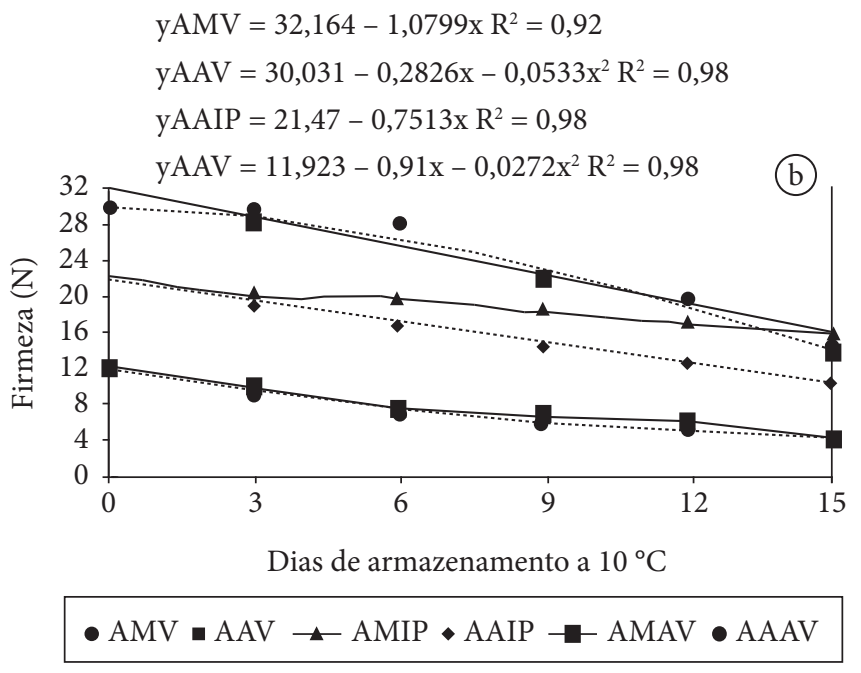

Figura 3. Firmeza em mangaba decorrente do estádio de maturação, atmosfera e temperatura, durante o armazenamento sob a condição ambiente $\left(\mathrm{A}-23 \pm 2{ }^{\circ} \mathrm{C}\right)$ e sob refrigeração $\left(\mathrm{B}-10 \pm 0,5^{\circ} \mathrm{C}\right)$. Linha cheia: $\mathrm{AM}=$ atmosfera modificada; linha tracejada: $\mathrm{AA}=$ atmosfera ambiente; $\mathrm{AMV}$ = atmosfera modificada e estádio de maturação verde; $\mathrm{AAV}=$ atmosfera ambiente e estádio de maturação verde; AMIP = atmosfera modificada e estádio de maturação início da pigmentação; AAIP = atmosfera ambiente e estádio de maturação início da pigmentação; AMAV = atmosfera modificada e estádio de maturação amarelo com leves manchas vermelhas; e AAAV = atmosfera ambiente e estádio de maturação amarelo com leves manchas vermelhas. 
ser convertidos em açúcares elevando, assim, o teor de sólidos solúveis (KAYS, 1997).

De acordo com a Figura 5, observou-se que frutos no estádio AV apresentaram valores mais elevados de Acidez Titulável (AT), independentemente da atmosfera e da temperatura avaliada, verificando-se também pouca oscilação dos valores de AT, para os frutos no estádio V e IP sob condição ambiente. A diminuição da concentração dos ácidos durante os períodos de armazenamento pode estar relacionada com a utilização dos ácidos como substrato da respiração (CHITARRA; CHITARRA, 2005). Verificou-se que mangabas no estádio AV apresentaram menores valores de $\mathrm{pH}$, independentemente da temperatura de armazenamento, contrastando com os resultados observados para AT (Figura 6).

Observou-se também que os valores de $\mathrm{pH}$, para frutos colhidos nos estádios V e IP, não apresentaram diferença entre os tratamentos avaliados durante o armazenamento de frutos mantidos sob condição ambiente.

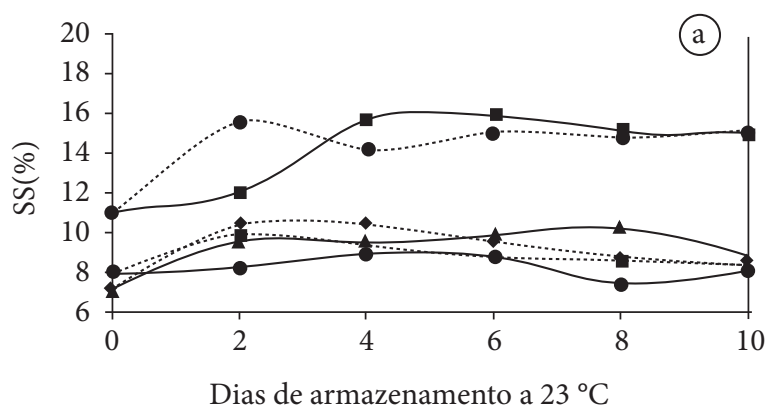

$-\mathrm{AMV} \cdots \mathrm{AAV} \leadsto \mathrm{AMIP} \cdots \mathrm{AAIP} \backsim \mathrm{AMAV} \cdots \mathrm{AAAV}$

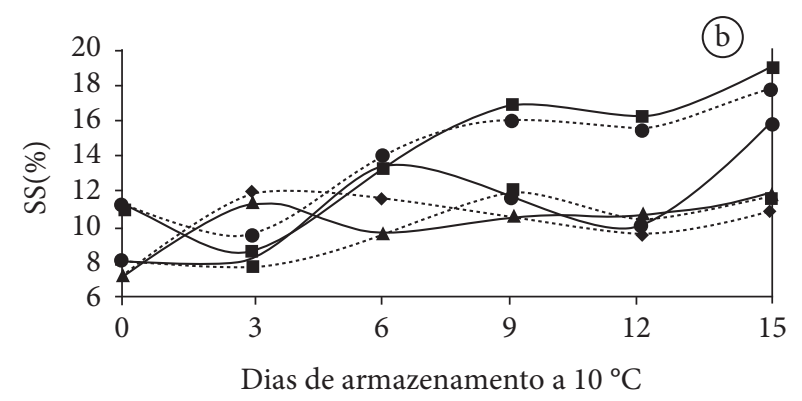

$\bullet \mathrm{AMV} \backsim \mathrm{AAV} \rightarrow \mathrm{AMIP} \cdots \cdots \mathrm{AAIP} \rightarrow \mathrm{AMAV} \cdots \bullet \cdots \mathrm{AAAV}$

Figura 4. Sólidos Solúveis (SS) em mangaba decorrente do estádio de maturação, atmosfera e temperatura, durante o armazenamento sob a condição ambiente $\left(\mathrm{A}-23 \pm 2{ }^{\circ} \mathrm{C}\right)$ e sob refrigeração $\left(\mathrm{B}-10 \pm 0,5^{\circ} \mathrm{C}\right)$. Linha cheia: $\mathrm{AM}=$ atmosfera modificada; linha tracejada: $\mathrm{AA}$ - atmosfera ambiente; $\mathrm{AMV}$ = atmosfera modificada e estádio de maturação verde; $\mathrm{AAV}=$ atmosfera ambiente e estádio de maturação verde; AMIP = atmosfera modificada e estádio de maturação início da pigmentação; AAIP = atmosfera ambiente e estádio de maturação início da pigmentação; AMAV = atmosfera modificada e estádio de maturação amarelo com leves manchas vermelhas; e AAAV = atmosfera ambiente e estádio de maturação amarelo com leves manchas vermelhas.
A relação SS/AT (Figura 7) apresentou oscilação durante o armazenamento tanto para os frutos armazenados sob condições ambientes quanto naqueles sob refrigeração, para as duas condições atmosferas avaliadas.

A evolução da coloração da casca de mangabas colhidas no estádio amarelo com leves manchas vermelhas (AV) ocorreu gradativamente até o estádio em que a coloração do fruto atingiu $70 \%$ da sua superfície vermelha e 30\% amarelo-escuro, no décimo dia de armazenamento, para os frutos mantidos sob AA e sob condição ambiente e, no décimo quinto dia de armazenamento, para os frutos sob refrigeração (Figura 8). Observou-se que os frutos sob AA apresentaram evolução mais rápida da coloração ao final do período de armazenamento, independentemente da temperatura avaliada.

Os frutos classificados no escore 4 apresentavam-se com coloração da casca amarelo avermelhado, estádio de comercialização, indicando, portanto, que os frutos no estádio $\mathrm{V}$ mantidos

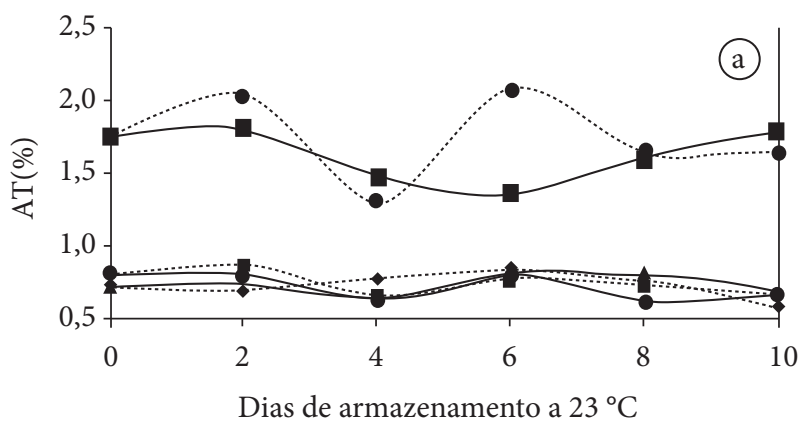

$-\mathrm{AMV} \cdots \mathrm{AAV} \leadsto \mathrm{AMIP} \cdots \mathrm{AAIP}$ AMAV AAAV

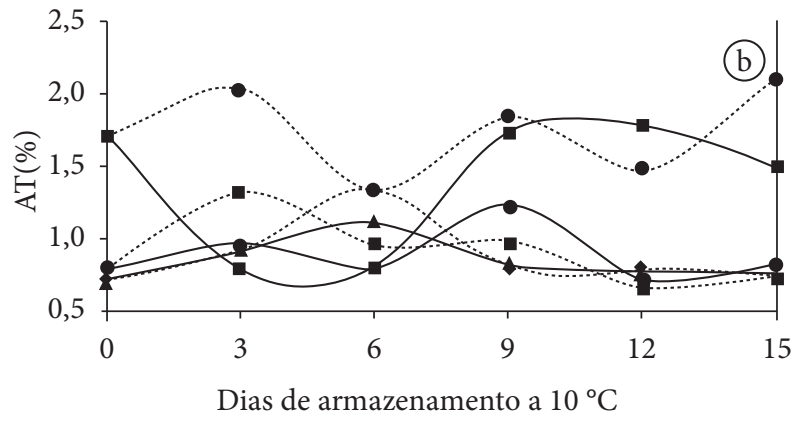

$\bullet$ AMV $\cdots \cdots \mathrm{AAV} \_\mathrm{AMIP} \cdots \mathrm{AAIP}$ AMAV AAAV

Figura 5. Acidez Titulável (AT) em mangaba decorrente do estádio de maturação, atmosfera e temperatura, durante o armazenamento sob a condição ambiente $\left(\mathrm{A}-23 \pm 2{ }^{\circ} \mathrm{C}\right)$ e sob refrigeração $\left(\mathrm{B}-10 \pm 0,5^{\circ} \mathrm{C}\right)$. Linha cheia: $\mathrm{AM}=$ atmosfera modificada; linha tracejada: $\mathrm{AA}=$ atmosfera ambiente; $\mathrm{AMV}=$ atmosfera modificada e estádio de maturação verde; $\mathrm{AAV}$ = atmosfera ambiente e estádio de maturação verde; AMIP = atmosfera modificada e estádio de maturação início da pigmentação; AAIP = atmosfera ambiente e estádio de maturação início da pigmentação; $A M A V$ = atmosfera modificada e estádio de maturação amarelo com leves manchas vermelhas; e AAAV = atmosfera ambiente e estádio de maturação amarelo com leves manchas vermelhas. 
sob refrigeração apresentaram retardamento no desenvolvimento da coloração e, consequentemente, do amadurecimento, provavelmente em decorrência da sensibilidade de estádios de maturação mais prematuros a baixas temperaturas de armazenamento, que pode ter afetado a atividade enzimática de modo a afetar o metabolismo dos pigmentos (KAYS, 1997), sobretudo para frutos mantidos sob AA. Este comportamento pode ser associado também à ocorrência de dano pelo frio, verificada para frutos desse estádio de maturação, afetando principalmente o metabolismo de degradação da clorofila.

Mangabas mantidas sob AM por filme de PVC apresentavam-se livres de danos pelo frio e/ou infecção fúngica e, portanto, tinham a aparência aceitável para o consumo (escore 4) até o décimo quinto dia de armazenamento à temperatura de refrigeração para frutos colhidos nos três estádios de maturação avaliados.

A aparência de mangabas colhidas no estádio AV, mantidas sob AM, apresentou valores mais elevados quando comparados àqueles sob AA, durante o armazenamento. Observou-se que

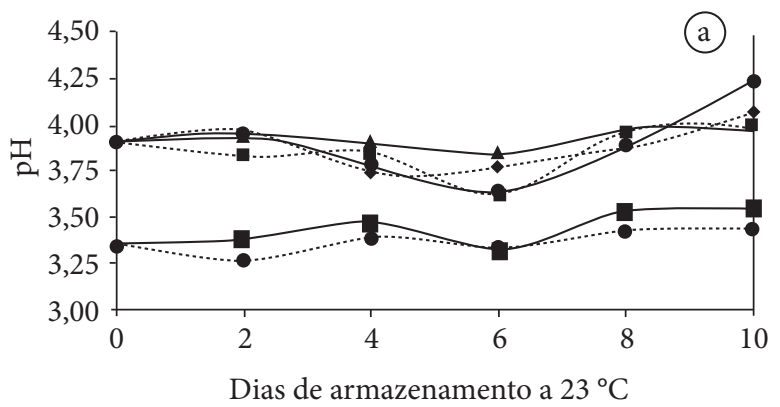

$\bullet-\mathrm{AMV} \cdots \mathrm{AAV} \multimap \mathrm{AMIP} \cdots \cdots \mathrm{AAIP} \rightarrow \mathrm{AMAV} \cdots \bullet \cdots \mathrm{AAAV}$

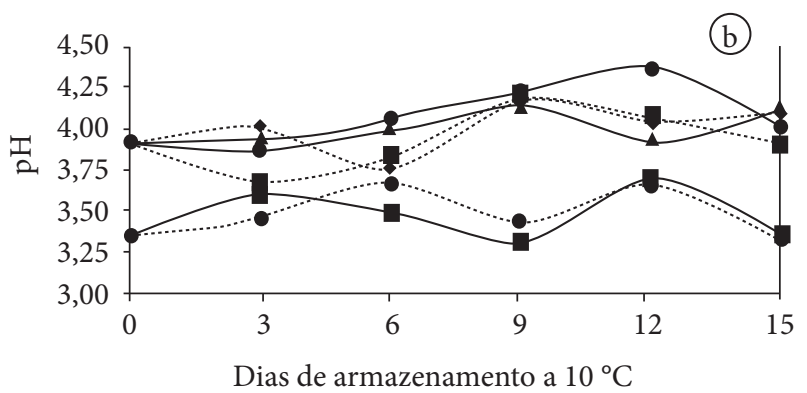

$-\mathrm{AMV} \cdots \mathrm{AAV} \rightarrow \mathrm{AMIP} \cdots \cdots \mathrm{AAIP} \_$- AMAV $\cdots \bullet \cdots \mathrm{AAAV}$

Figura 6. pH em mangaba decorrente do estádio de maturação, atmosfera e temperatura, durante o armazenamento sob a condição ambiente $\left(A-23 \pm 2{ }^{\circ} \mathrm{C}\right)$ e sob refrigeração $\left(B-10 \pm 0,5^{\circ} \mathrm{C}\right)$. Linha cheia: $\mathrm{AM}=$ atmosfera modificada; linha tracejada: $\mathrm{AA}=$ atmosfera ambiente; $\mathrm{AMV}$ = atmosfera modificada e estádio de maturação verde; $\mathrm{AAV}$ = atmosfera ambiente e estádio de maturação verde; AMIP = atmosfera modificada e estádio de maturação início da pigmentação; AAIP = atmosfera ambiente e estádio de maturação início da pigmentação; $\mathrm{AMAV}$ = atmosfera modificada e estádio de maturação amarelo com leves manchas vermelhas; e AAAV = atmosfera ambiente e estádio de maturação amarelo com leves manchas vermelhas. os frutos no estádio Verde (V) sob refrigeração apresentaram índices de dano pelo frio, verificando-se que frutos pré-maturos são mais susceptível a essa desordem fisiológica (KAYS, 1997), consequentemente, ao não desenvolvimento da coloração. Frutos mantidos sob AM mantiveram melhor aparência durante o período de armazenamento (Figura 9), como também reportado para pitanga armazenada sob condições similares (SANTOS et al., 2006).

A refrigeração prolongou a vida útil dos frutos durante os 15 dias de armazenamento. Mangabas são frutos que possuem atividade metabólica elevada e consequentemente, vida pós-colheita curta. De acordo com Kader (1986), a maioria dos processos que conduzem à perda de qualidade está relacionada à temperatura e umidade relativa do ambiente de armazenamento. A temperatura determina a quantidade de vapor de água necessária para saturar a atmosfera, afetando a fisiologia do produto e/ou desenvolvimento de microrganismos (SMITH et al., 1987).

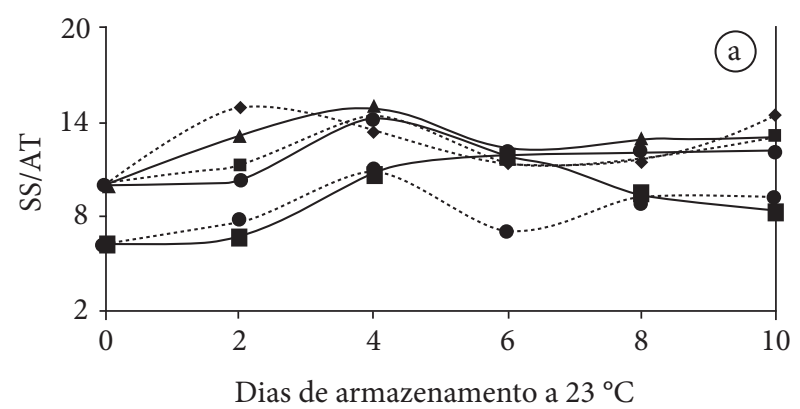

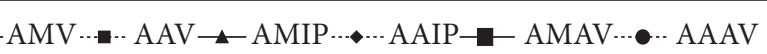

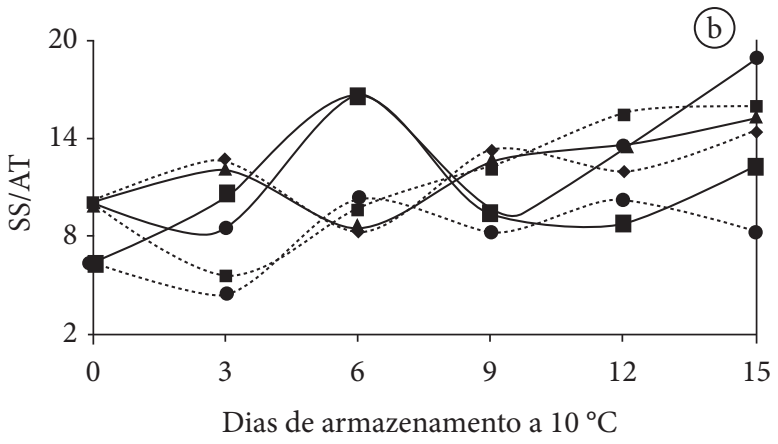

$-\mathrm{AMV} \cdots \mathrm{AAV} \rightarrow \mathrm{AMIP} \cdots \cdots$ AAIP

AMAV $\cdots$

AAAV

Figura 7. Relação SS/AT, em mangaba decorrente do estádio de maturação, atmosfera e temperatura, durante o armazenamento sob a condição ambiente $\left(\mathrm{A}-23 \pm 2{ }^{\circ} \mathrm{C}\right)$ e sob refrigeração $\left(\mathrm{B}-10 \pm 0,5^{\circ} \mathrm{C}\right)$. Linha cheia: $\mathrm{AM}=$ atmosfera modificada; linha tracejada: $\mathrm{AA}=$ atmosfera ambiente; $\mathrm{AMV}$ = atmosfera modificada e estádio de maturação verde; $\mathrm{AAV}=$ atmosfera ambiente e estádio de maturação verde; AMIP = atmosfera modificada e estádio de maturação início da pigmentação; AAIP = atmosfera ambiente e estádio de maturação início da pigmentação; AMAV = atmosfera modificada e estádio de maturação amarelo com leves manchas vermelhas; AAAV = atmosfera ambiente e estádio de maturação amarelo com leves manchas vermelhas. 


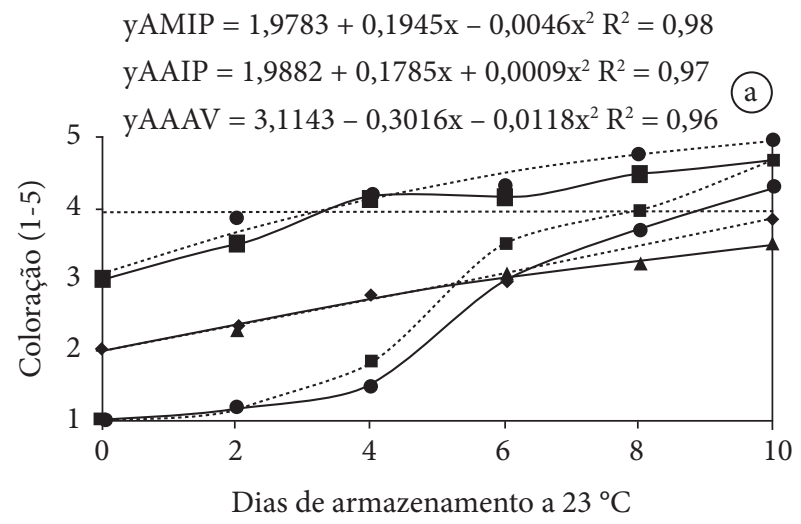

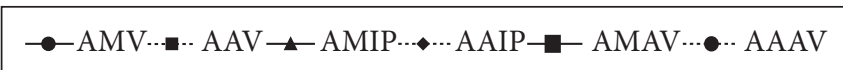

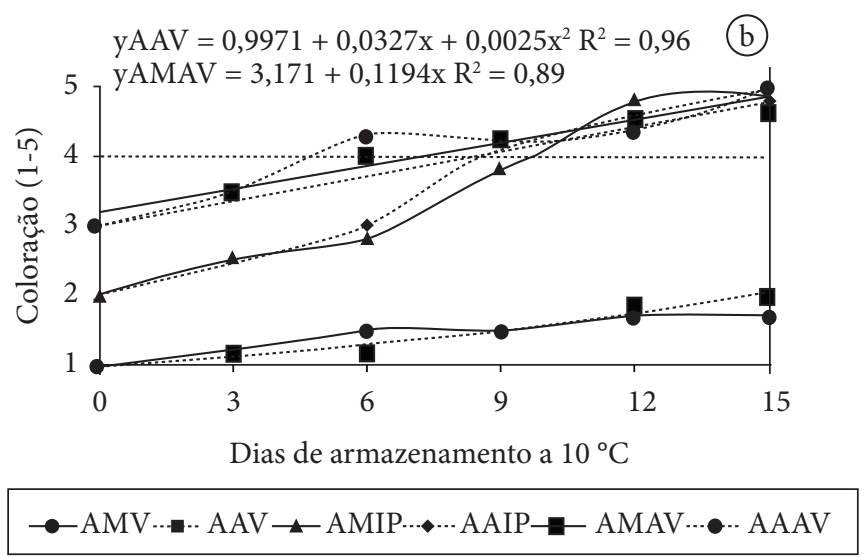

Figura 8. Evolução da coloração (1-5) em mangaba decorrente do estádio de maturação, atmosfera e temperatura, durante o armazenamento sob a condição ambiente $\left(\mathrm{A}-23 \pm 2{ }^{\circ} \mathrm{C}\right)$ e sob refrigeração $\left(\mathrm{B}-10 \pm 0,5^{\circ} \mathrm{C}\right)$. Linha cheia: $\mathrm{AM}=$ atmosfera modificada; linha tracejada: $\mathrm{AA}=$ atmosfera ambiente; $\mathrm{AMV}=$ atmosfera modificada $\mathrm{e}$ estádio de maturação verde; AAV = atmosfera ambiente e estádio de maturação verde; AMIP = atmosfera modificada e estádio de maturação início da pigmentação; AAIP = atmosfera ambiente e estádio de maturação início da pigmentação; AMAV = atmosfera modificada e estádio de maturação amarelo com leves manchas vermelhas; e AAAV $=$ atmosfera ambiente e estádio de maturação amarelo com leves manchas vermelhas.

\section{Conclusões}

- O uso da atmosfera modificada por filme de PVC de $13 \mu \mathrm{m}$ de espessura é eficiente na conservação de mangabas colhidas nos três estádios de maturação, sobretudo para as do estádio amarelo com leves manchas vermelhas (AV) e sob refrigeração;

- Mangabas colhidas no estádio amarelo com leves manchas vermelhas $(\mathrm{AV})$ desenvolvem a cor atrativa quando sob refrigeração, mantendo a qualidade em condições aceitáveis, apresentando menor perda de massa, conservando a integridade, a turgidez, a aparência atrativa e ausência de infestação por fungos; e

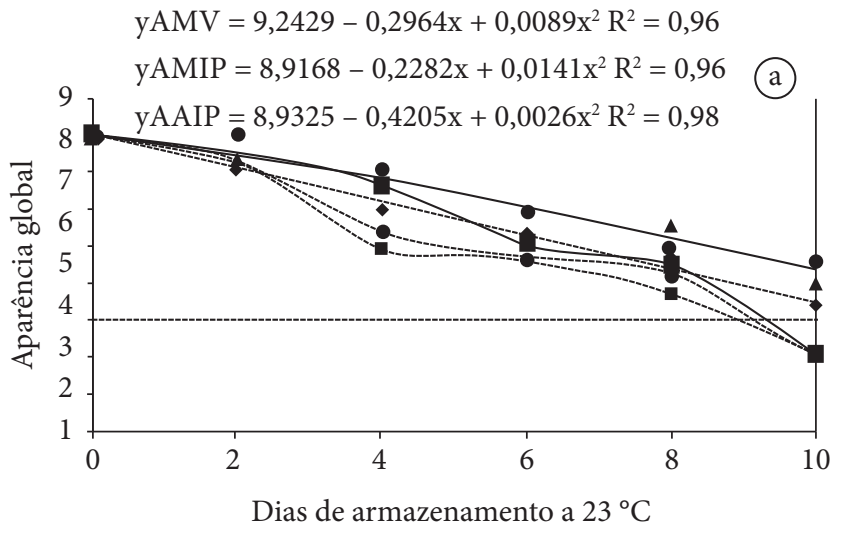

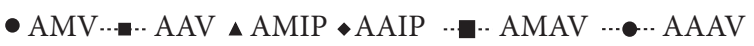

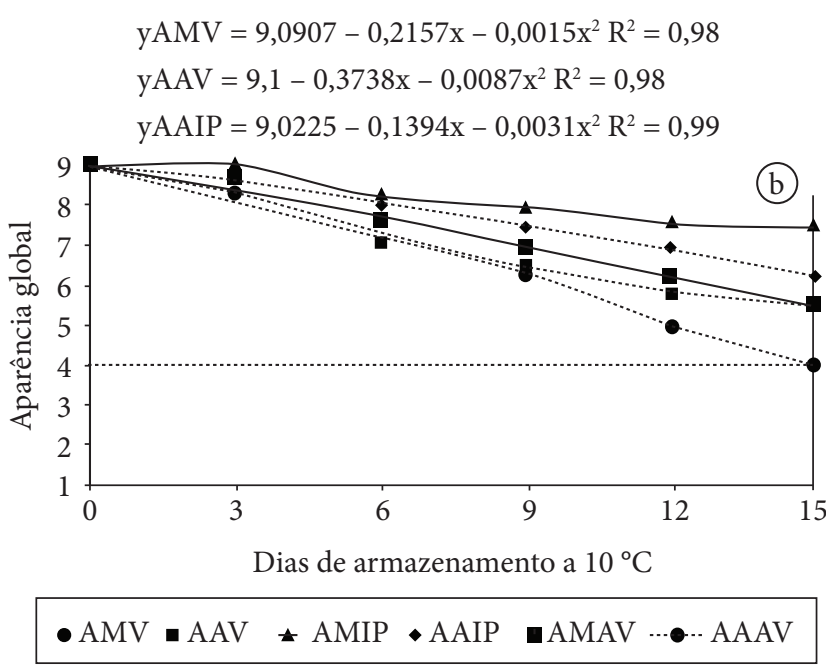

Figura 9. Aparência global em mangaba decorrente do estádio de maturação, atmosfera e temperatura, durante o armazenamento sob a condição ambiente $\left(\mathrm{A}-23 \pm 2^{\circ} \mathrm{C}\right)$ e sob refrigeração $\left(\mathrm{B}-10 \pm 0,5^{\circ} \mathrm{C}\right)$. Linha cheia: $\mathrm{AM}=$ atmosfera modificada; linha tracejada: $\mathrm{AA}=$ atmosfera ambiente; $\mathrm{AMV}=$ atmosfera modificada e estádio de maturação verde; $\mathrm{AAV}$ = atmosfera ambiente e estádio de maturação verde; AMIP = atmosfera modificada e estádio de maturação início da pigmentação; AAIP = atmosfera ambiente e estádio de maturação início da pigmentação; AMAV = atmosfera modificada e estádio de maturação amarelo com leves manchas vermelhas; e AAAV = atmosfera ambiente e estádio de maturação amarelo com leves manchas vermelhas.

- Frutos colhidos no estádio verde (V) e mantidos sob refrigeração desenvolvem sintomas de danos pelo frio, apresentando inibição no desenvolvimento da pigmentação e amadurecimento comprometido.

\section{Referências bibliográficas}

ALVES, R. E. et al. A cultura da mangaba. Aracaju: Embrapa Tabuleiros Costeiros, 2006. cap 16, p. 207-220.

BEN-ARIE, R.; ZUTKHI, Y. Extending the storage life of Fuyu persmimmon by modified atmosphere packaging. HortScience, v. 27, n. 7, p. $811-813,1992$. 
BEN-YEHOSHUA, S. Transpiration, water stress and gas exchange. In: WEICHMANN, J. Postharvest Physiology of Vegetables. New York: Marcel Dekker, 1987. 113-170 p.

BORGES, M. F.; FILGUEIRAS, H. A. C.; MOURA, C. F. H. Mangaba (Hancornia speciosa Gomes). In: ALVES, R. E.; FILGUEIRA, H. A. C.; MOURA, C. F. H. (Eds.). Caracterização de frutas nativas da América Latina. Jaboticabal: FUNEP, 2000. cap. 12, p. 44-45. (Série Frutas Tropicais).

CARNELOSSI, M. A. G. et al. Conservação pós-colheita de mangaba (Hancornia speciosa Gomes). Revista Ciência e Agrotecnologia, v. 28, n. 5, p. 1119-1125, 2004.

CHITARRA, M. I. F.; CHITARRA, A. B. Pós-colheita de frutas e hortaliças: fisiologia e manuseio. 2 ed. Lavras: UFLA, 2005. 783p.

KADER, A. A. Biochemical and physiological basis for effects of controlled and modified atmospheres on fruits and vegetables. Food Technology, v. 40, n. 5, p. 99-104, 1986.

KAYS, S. J. Postharvest Physiology of Perishable Plant Products. Athens: Exon Press, 1997. 532p.

LEDERMAN, I. E. et al. Mangaba (Hancornia speciosa Gomes). Jaboticabal: São Paulo, 2000. 35p. (Série Frutas Nativas, 2).
INSTITUTO ADOLFO LUTZ. Métodos físico-químicos para análise de alimentos. 4 ed. São Paulo: Editora do IAL, 2005. 1070 p.

MANICA, I. Frutas Nativas, Silvestres e Exóticas 2: técnicas de produção e mercado: feijoa, figo- da- índia, fruta-pão, jaca, lichia, mangaba. Porto Alegre: Cinco Continentes Editora, 2002. p. $459-541$.

MEDINA, P. V. L. Manejo Pós-colheita de pimentões e pimentas. Informe Agropecuário, v. 10, n. 113, p. 72-76, maio 1984.

MOURA, F. T. Fisiologia da maturação e conservação pós-colheita de mangaba. Areia, 2005. 98p. Dissertação (Mestrado em Agronomia) - Universidade Federal da Paraíba - UFPB.

SMITH, S.; GEESON, J.; STOW, J. Production of modified atmospheres in deciduous fruits by the use of films and coatings. HortScience, v. 22 , n. 5 , p. $772-776,1987$.

VIEIRA NETO, R. D. Caracterização física de frutos de uma população de mangabeiras (Hancornia speciosa Gomes). Revista Brasileira de Fruticultura, v. 19, n. 2, p. 247-250, 1997.

VILLACHICA, H. Mangaba (Hancornia speciosa Gomes). In: VILLACHICA, H. Frutales y hortalizas promissorios de la amazonia. Lima: TCA, 1996. p. 90-194. 